OPEN ACCESS

Edited by:

Stefania Raimondo,

University of Turin, Italy

Reviewed by:

Giovanni Vozzi, University of Pisa, Italy

Federica Fregnan,

University of Turin, Italy

*Correspondence:

A. Boecker

arnehendrik.boecker@

bgu-ludwigshafen.de

Received: 28 October 2018

Accepted: 28 February 2019

Published: 04 April 2019

Citation:

Boecker A, Daeschler SC

Kneser U and Harhaus L (2019)

Relevance and Recent Developments

of Chitosan in Peripheral

Nerve Surgery.

Front. Cell. Neurosci. 13:104.

doi: 10.3389/fncel.2019.00104

\section{Relevance and Recent Developments of Chitosan in Peripheral Nerve Surgery}

\author{
A. Boecker*, S. C. Daeschler, U. Kneser and L. Harhaus
}

1 Department of Hand, Plastic and Reconstructive Surgery, Burn Center, BG Trauma Center Ludwigshafen, University of Heidelberg, Ludwigshafen, Germany

Developments in tissue engineering yield biomaterials with different supporting strategies to promote nerve regeneration. One promising material is the naturally occurring chitin derivate chitosan. Chitosan has become increasingly important in various tissue engineering approaches for peripheral nerve reconstruction, as it has demonstrated its potential to interact with regeneration associated cells and the neural microenvironment, leading to improved axonal regeneration and less neuroma formation. Moreover, the physiological properties of its polysaccharide structure provide safe biodegradation behavior in the absence of negative side effects or toxic metabolites. Beneficial interactions with Schwann cells (SC), inducing differentiation of mesenchymal stromal cells to SC-like cells or creating supportive conditions during axonal recovery are only a small part of the effects of chitosan. As a result, an extensive body of literature addresses a variety of experimental strategies for the different types of nerve lesions. The different concepts include chitosan nanofibers, hydrogels, hollow nerve tubes, nerve conduits with an inner chitosan layer as well as hybrid architectures containing collagen or polyglycolic acid nerve conduits. Furthermore, various cell seeding concepts have been introduced in the preclinical setting. First translational concepts with hollow tubes following nerve surgery already transferred the promising experimental approach into clinical practice. However, conclusive analyses of the available data and the proposed impact on the recovery process following nerve surgery are currently lacking. This review aims to give an overview on the physiologic properties of chitosan, to evaluate its effect on peripheral nerve regeneration and discuss the future translation into clinical practice.

Keywords: microsurgery, peripheral nerve injuries, nerve surgery, nerve regeneration, nerve reconstruction, chitosan, nerve growth factors

Abbreviations: BMSC, bone marrow mesenchymal stromal cells; CCL2, chemokine ligand 2; DOA, degree of acetylation; EGR2, early growth response protein 2; FGF-2, fibroblast growth factor-2; GDNF, glial cell line-derived growth factor; NCAM, neural cell adhesion molecule; NGF, nerve growth factor; PDGF, platelet-derived growth factor (PDGF); PGA, poly glycolic acid; PLA, polylactic acid; PLGA, poly(lactic-co-glycolic acid); PNI, peripheral nerve injury; SC, Schwann cells. 


\section{INTRODUCTION}

Approximately $2.8 \%$ of all hospitalized trauma patients suffer from traumatic peripheral nerve injury (Noble et al., 1998). The related severe functional impairment, as well as the consequent socio-economic impact, led to continuous research efforts in this field (Nicholson and Verma, 2004). If a direct tension free approximation of the nerve stumps is possible, to this day, the epineural nerve suture represents the first line therapy. Alternatively, if tension free coaptation is not achievable, the autologous nerve transplantation (ANT) is the current gold standard (Deumens et al., 2010). However, given the limited availability of donor nerves and the associated donor site morbidity, new approaches are needed to support in peripheral nerve surgery. Ideally, nerve conduits could provide guidance for the regenerating axons toward the distal nerve stump in the absence of negative side effects like an extended foreign body reaction or an undirected axonal regeneration. Tissue engineering utilized a considerable diversity of materials, but basic techniques like the ANT, firstly described in the 1970's, are still up to date (Davis and Perret, 1946; Tarlov et al., 1946). Various materials have been tested for bridging peripheral nerve defects reaching from non-resorbable materials like silicon (Lundborg, 2004) to fully biodegradable materials such as Collagen or PGA (Inada et al., 2007; Bozkurt et al., 2012; Boecker et al., 2015). Today, it is a common consent that the material used to support the peripheral nerve regeneration should ideally base on a fully degradable matrix without negatively influencing the regeneration during biodegradation process (Schmidt and Leach, 2003). However, despite substantial developments in tissue engineering, there is still no material or bio-mimicking concept, which revealed superior results in peripheral nerve regeneration compared to the ANT as the current gold standard for bridging peripheral nerve defects (Deumens et al., 2010).

Besides the already established materials, Chitosan is a promising relatively novel material in the field of peripheral nerve regeneration. As it is based on the shell of arthropods it is universally available at low costs and provides a fully bioresorbable structure in the absence of toxic metabolites, potentially interfering the regeneration process (Freier et al., 2005b). Moreover, its specific physical and chemical properties enable to simulate the physiological multilayer architecture of peripheral nerves in artificial tissue engineered nerve conduits. This provides a wide field of potential applications in peripheral nerve surgery such as gap bridging, nerve suture protection or even neuroma prevention.

Previous preclinical and clinical studies investigated these conditions and demonstrated chitosan to support the axonal regeneration (Haastert-Talini et al., 2013; Stenberg et al., 2016), reduce extensive scarring, improve functional recovery (Neubrech et al., 2018) and prevent neuroma formation following peripheral nerve injury (Marcol et al., 2011). These promising preclinical and early clinical experiences in diverse nerve injury models along with its physiologic features emphasize the future potential of chitosan-based matrices in reconstructive nerve surgery. This work aims to systematically review the current tissue engineering strategies and the current process of clinical implementation.

\section{PROPERTIES OF CHITOSAN AND ITS IMPACT ON PERIPHERAL NERVE REGENERATION}

The basic component of Chitosan is Chitin, a long-chain polymer of $\mathrm{N}$-acetylglucosamine which is harvested by the exoskeletons of arthropods. After cellulose, Chitin is the second most abundant polysaccharide in nature and is aimed to be mainly used in its deacetylated modification (Chitosan) in the field of peripheral nerve surgery (Crompton et al., 2007). Chitin and chitosan can be classified into the family of the glycosaminoglycans, related to groups of chondroit sulfates, hyaluronic acid, and heparins. However, glycosaminoglycans may be the only polysaccharides with bioactive capabilities (Struszczyk, 2002). Chitin consists of a linear homopolymer of $N$-acetyl-D-glucosamine units with $\beta$-(14)-linkages. After partial deacetylation, chitin becomes chitosan (see Figure 1). Thus it can be can be easily obtained at very low production costs for commercial purposes by alkaline hydrolysis of chitin (Freier et al., 2005b). Depending on the processing of the chitosan, the degree of acetylation (DOA) can be varied and thus influences the molar mass as well as solvent characteristics (Chatelet et al., 2001).

Moreover, the DOA has also been shown to be a relevant factor, influencing survival, proliferation and cell activity of regeneration supporting cells like SC (Carvalho et al., 2017). But, the exact adjustments of chitosan matrices remain challenging, because the mechanical stiffness, the biodegradation time, the geometric architecture as well as the sterilization method potentially influence the axonal regeneration process and thus need to be taken into account throughout the manufacturing process (Stößel et al., 2018).

In tissue engineered nerve conduits, the biodegradation and physiologic replacement processes start immediately and thus present the central mechanisms of action which influence nerve recovery. In contrast to acid-based materials, like polyglycolic acid (PGA) or polylactide derivates, which undergo a ph decrease during biodegradation or signs of inflammatory foreign body reaction (Meek and Coert, 2008), metabolites of chitosan demonstrated neuroprotective effects during peripheral nerve regeneration.

Here, a degradation product of Chitosan, the Chitooligosaccharide (COS), has been found to promote cell proliferation and prevent apoptosis especially for SC, as the

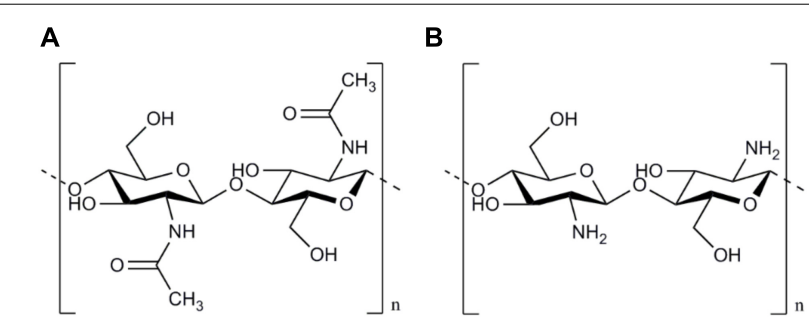

FIGURE 1 | Chemical structure of Chitin and Chitosan. The chemical structure of Chitin based on a linear homopolymer of $N$-acetyl-D-glucosamine units (A). After partial deacetylation chitin becomes chitosan mainly used in peripheral nerve surgery (B). 
vital cell for a sufficient axonal regeneration (Zhou et al., 2008; Huang et al., 2015). Furthermore, Wang et al. (2016) attributed these stimulating effects of COS to an accelerated cell cycle leading to increased SC proliferation.

Moreover, COS stimulate the CCL2 expression by downregulating the miR-327 of the SC, resulting in enhanced macrophage migration to the injury site (Zhao et al., 2017). In line with this, Bin et al. analyzed the anti-apoptotic effects of carboxymethylated chitosan (CMC) on SC by decreasing caspase-3, - 9 and Bax activities and increasing Bcl-2 activities in CMC treated SC. To prevent the SC against oxidative stress, COS led to a reduced activity of malondialdehyde as well as to increased activity of superoxide dismutase activities (SOD) (He et al., 2014). Further in vivo experiments demonstrated a significantly improved peripheral nerve regeneration following daily intravenous injection COS for 6 weeks in an axonotmesis rabbit animal model. Interestingly, the number of regenerated myelinated nerve fibers, the myelin sheath thickness, as well as the compound muscle action potential (CMAP) as the parameter for electrophysiological recovery, has been shown to be significantly superior in COS treated animals. Thus, Gong et al. (2009) sum up, that COS not only accelerate the peripheral nerve regeneration but also can be seen as a neuroprotective agent after PNI.

Furthermore, the beneficial effect on neural disorders by suppression of the $\beta$-amyloid formation and supporting the anti-neuroinflammatory activity underlines the tremendous potential of COS, and consequently of chitosan, in the field of neuropathologies (Pangestuti and Kim, 2010; Hao et al., 2017).

Focusing on the tissue engineered designs, in most publications, Chitosan is the main component for a new tissue-engineered nerve conduit to bridge peripheral nerve defects. Interestingly, there are some alternative geometric structures of chitosan to promote axonal regeneration or even prevent neuroma formation.

$\mathrm{Xu}$ et al. (2017) have recently published another concept in the tissue engineering of chitosan by presenting a chitosan-based hydrogel in combination with a poly 3,4ethylenedioxythiophene. Supported cell adhesion, vitality, and proliferation of PC-12 cells underline the potential of chitosan hydrogel for further neural tissue engineering. Interestingly tissue engineered concepts based on chitosan focused not only on the treatment of PNI but also for neuroma prevention. Marcol et al. (2011) applied, mircrocrystallic chitosan to the proximal nerve stump after PNI and showed less autotomy behavior and minor axonal sprouting as a key ability for neuroma prevention in the future.

\section{MECHANICAL PROPERTIES AND TOPOGRAPHIC STRATEGIES IN TISSUE ENGINEERING OF CHITOSAN}

\section{Mechanical Properties and Challenges}

In a medical application, chitosan has already a long history due to its biocompatibility and to its non-toxic, biodegradable properties (Freier et al., 2005b).
Not only in the field of peripheral nerve surgery chitosan plays a crucial role, but also for wound healing or as a drug delivery system. Referring to the peripheral nerve, low mechanical strength has been a tremendous challenge in the early phase after implantation of chitosan and its derivates. Matrices of chitosan showed decreased stability under physiological conditions (Madihally and Matthew, 1999; Itoh et al., 2003) and therefore make it not suitable for the translational application. Modifications have been made to improve mechanical stability by designing an internal architecture by puncturing the chitosan while molding procedures with needles (Wang et al., 2006). Alternatively, Ao et al. (2006) developed a new unidirectional temperature gradient leading to a chitosan scaffolds incorporated with longitudinal microfibers. Unfortunately, the scaffold presents an appropriate mechanical strength under in vitro conditions but fail to show stability under physiological in vivo circumstances. To improve the mechanical strength of chitosan, further adjustments like additional cross-linking by supplementation of chitin (Yang et al., 2004) or formaldehyde (Desai and Park, 2005) have been published. The mechanical stability of the chitosan is also affected by the degree of acetylation (DOA). Higher DOA has been reported to improve the stability of chitosan and lead to a superior keratinocytes cell adhesion (Chatelet et al., 2001). Referring to the neural cell lineage, acetylation rates of 0.5 and $11 \%$ showed more and longer neurites of regeneration of dorsal chick root ganglions neurons compared to other concentration. However, cell viability of $0.5 \%$ was approximately eight times higher compared to a DOA of $11 \%$. Thus, surface modifications of chitosan films referring to the cell viability and cell adhesion can clearly be modified by the DOA (Freier et al., 2005a) and needs to be addressed in the future tissue engineering for chitosan materials. In line with this, supporting cells, like SC, also benefit from a low DOA by presenting a better cell spreading and proliferation (Wenling et al., 2005).

However, for translation applications, the mechanical strength of the material to prevent the collapse of the material is essential as well as the ability for an inner lining of regenerating axons. Exemplary, Wang et al. present a chitosan two-layer approach with an oriented inner layer of nanofibers and a random outer layer with superior stability compared to random fiber mesh tubes (Wang et al., 2008a,b).

\section{Forms of Chitosan and Topographic Concepts}

Several forms and techniques of chitosan have been published in literature reaching from hydrogels (Zheng et al., 2010; Rickett et al., 2011; Nawrotek et al., 2016b; Du et al., 2017), films (Pavinatto et al., 2010; Xiao et al., 2013; Meyer et al., 2016b), microspheres (Zeng et al., 2014) or tubes (Itoh et al., 2003; Wang et al., 2006; Shapira et al., 2016) in the field of peripheral nerve surgery.

\section{Hydrogels}

Hydrogels are a frequently applied form in the field of tissue engineering because of the similarity to the extracellular matrix, and the modest way of processing.

Freier et al. (2005b) presented, after the hydrolyzation of chitin, a hydrogel-based chitosan tube with superior mechanical 
strength, measured by the transverse compressive test. Chitosan Hydrogel has also been used as an alternative to the fibrin glue or even to the epineural suture after peripheral nerve lesion (Rickett et al., 2011). Further in vitro studies combine chitosan hydrogels with hydroxyapatite as a source for calcium ions to modify mechanical and biological properties. Cytotoxic and pro-inflammatory tests could mark the biocompatibility of this hydrogel solution independently of the tested composition (Nawrotek et al., 2016a).

Interestingly, in vivo studies with a chitosan/glycerol-betaphosphate disodium salt hydrogel presented an impaired peripheral nerve regeneration for $10 \mathrm{~mm}$ sciatic nerve defect compared to chitosan tubes filled with SC suspension or culture medium (Zheng et al., 2010). Hydrogels as an inner filling in combination with chitosan tubes tested under in vivo conditions led to further enhanced peripheral nerve regeneration.

As drug delivery system, chitosan hydrogels have also been explored by a continuous delivery of methylprednisolone. Functional recovery of the rat's facial (Chao et al., 2015) and sciatic nerve (Mehrshad et al., 2017) was accelerated for animals with a supplementary methylprednisolone delivery.

Hydrogels of other components, like Hyaluronic hydrogels (Meyer et al., 2016b) fibrin nanofiber hydrogels (Du et al., 2017) or simvastatin/Pluronic F-127 hydrogels (Guo et al., 2018) have been frequently combined with chitosan tubes. Axonal regeneration and motor functional recovery was improved by applying these hydrogels as inner filling for chitosan tubes.

\section{Films}

In the field of peripheral nerve surgery, chitosan films are applied directly for enhancing peripheral nerve regeneration but also as an inner architecture for nerve guides to bridge peripheral nerve defects. Mechanical stability and biocompatibility were proven for neural cells and peripheral nerves tissue engineering (Pavinatto et al., 2010).

Meyer et al. (2016a) combined a chitosan nerve tube with a supporting inner layer of a chitosan film over $15 \mathrm{~mm}$ long distance defects of a rat's sciatic nerve lesion and presented superior axonal regeneration as well functional recovery compared to hollow non-modified chitosan tubes.

Chitosan films have been modified with several other components by crosslinking or incorporation. Proanthocyanidin was crosslinked to chitosan films with gelatine and showed improved mechanical properties, a decreased biodegradation rate, superior cell adhesion as well as improved proliferation compared to non-crosslinked gelatin or chitosan alone (Kim et al., 2005). Similar results have been found by the crosslinking of chitosan and hyaluronic in a polyelectrolyte multilayer film (Schneider et al., 2007). Incorporation of polyethylene oxid with chitosan revealed a superior water permeability and a ratio-depended antibacterial effects as well as improved mechanical strength compared to non-modified chitosan films (Zivanovic et al., 2007).

\section{Microspheres}

Chitosan can also be manufactured as microspheres or microparticles mainly used for drug delivery. Chitosan microspheres loaded with NGF has been incorporated to collagen-chitosan scaffolds for a rat's sciatic nerve and led to promising results in functional outcome in combination with microchannels as inner lining (Zeng et al., 2014) as well as combined with a chitosan nerve guide conduit for reconstruction of facial nerve injuries (Liu et al., 2013). Further developments in tissue engineering enable an additional loading of cores-shell poly(lactide-co-glycolide)-chitosan microparticles as drug delivery system for continuous release of NGF (Zhang et al., 2017).

\section{Tubes and Inner Architecture}

Different strategies of the treatment of peripheral nerve injuries based on chitosan have been explored in the literature, reaching from chitosan filament mesh tubes to chitosan-based nerve conduits. Exemplary, chitosan tubes were described by Suzuki et al. (2003) coupled with synthetized laminin under in vivo conditions to bridge a $15 \mathrm{~mm}$ sciatic nerve lesion. Despite the modification with the laminin peptides YIGSR and IKVAV, no superior results compared to the ANT have been shown (Suzuki et al., 2003). Further developments of tissue engineering led to chitosan tubes with a triangular inner surface and an additional coating with hydroxyapatite as well as laminin and laminin-1 peptides. Histological findings presented the beneficial effects of a triangular inner architecture for peripheral nerve regeneration. However, despite histological regeneration is like the ANT, delayed functional recovery was shown after 12 weeks of regeneration (Itoh et al., 2003). Addressing the essential need for inner guidance to bridge long distance peripheral nerve defects, porous chitosan tubular scaffold with chitosan fiberbased yarns with interconnected micropores were created (Wang et al., 2006). Wang et al. (2008a) also published alternative strategies for an inner lining by combining chitosan film tube as an outer layer with a nano/microfiber mesh as inner guidance. Different degrees of deacetylation were tested and compared to an ANT. Histological finding presents a better cell migration and attachment as well as neurite outgrowth for scaffolds with deacetylation rate of $93 \%$ compared to scaffolds with $78 \%$ (Wang et al., 2008a).

Furthermore, an additional mobilization with polarized $\beta$-tricalcium phosphate particles led to superior results in histological findings compared to non-polarized mesh tubes and similar results to the ANT (Wang et al., 2010). Silva et al. (2014) followed another approach presenting nanostructured hollow tubes with an additional crosslinking of genipin. Biological performance of this modified hollow tubes was assessed focussing on cell adhesion, viability, and proliferation (Silva et al., 2014). Recently, chitosan flat membranes crosslinked with dibasic sodium phosphate alone and combined with $\gamma$-glycidoxypropyltrimethoxysilan showed increased water stability and stiffness under in vitro conditions. For a $1 \mathrm{~cm}$ median nerve gap, chitosan conduits associated with $\gamma$-glycidoxypropyltrimethoxysilan promoted nerve fiber regeneration and functional recovery similar to the autograft (Fregnan et al., 2016).

Chitosan can also be combined with autologous materials by utilizing a chitosan tube with fresh skeletal muscle fibers as an 
inner layer to bridge nerve defects in the rat's median nerve. Interestingly, Neuregulin-1 is upregulated for chitosan tubes with internal muscle fibers but not for hollow tubes and may be crucial to further improve axonal nerve regeneration over long nerve lesions (Ronchi et al., 2018).

\section{Biochemical Properties and Surface Modifications}

Cell affinity for the neural cell lineage plays a crucial role to support neural regeneration. Therefore, chitosan is loaded with laminin or poly-lysine and led mainly to superior neurite outgrowth compared to the non-blended alternative (Haipeng et al., 2000). Cheng et al. (2004) applied PC12 cell culture to test cell affinity in poly-L-lysine different blended chitosan nerve tubes. Interestingly, the hydrophobicity of the poly-L-lysine in combination with the increased surface charge might be the reason for the increased cell attachment, growth, and differentiation (Cheng et al., 2004). Furthermore, increased concentration of poly-D-lysine not influence cell survival but can inhibit neurite outgrowth (Crompton et al., 2007).

Compositions of chitosan and gelatin have also been tested referring to the cell affinity and the potential to neurite outgrowth. Despite a decreased cell viability, chitosan blended with gelatine was able to show superior neurite outgrowth and in the first days of cell culture compared to PLL containing materials (Martín-López et al., 2012).

Alternative surface modification to promote peripheral nerve regeneration, are the YIGSR (Tyr-Ile-Gly-Ser-Arg) and IKVAV (Ile-Lys-Val-Ala-Val) sequences, which are known to modify receptor specific neural cell adhesion as well as to support neurite outgrowth. Itoh et al. (2005) were able to bond the YIGSR (Tyr-Ile-Gly-Ser-Arg) and IKVAV (Ile-Lys-Val-Ala-Val) peptides to molecular aligned chitosan. The peptides A3G75 and A3G83 of the laminin alpha chain LG4 modules promote neurite outgrowth. Conjugated peptides of the LG4 and LG5 modules to chitosan membranes presented improved cell attachment and neurite outgrowth for PC12 cells (Kato et al., 2002). A2G94 peptide is expressed by the Laminin alpha2 chain and led to a promoted alpha6beta1-mediated cell attachment as well as neurite outgrowth after conjugation in a chitosan tube (Urushibata et al., 2010).

Furthermore, Laminin-modified chitosan membranes significantly enhance SCs attachment and affinity for the guided peripheral nerve regeneration. Percentage of laminin incorporation is significantly higher by using the oxygen plasma technique compared to conventional chemical methods (Huang et al., 2007). Laminin has also been used to bond an additional glycin spacer to nano/microfiber mesh surface of the chitosan tube. SC affinity has been further improved by these surface modification (Huang et al., 2007). The combination of negatively charged heparin and positively charged $\gamma$-aminopropyltriethoxysilane (APTE) on porous chitosan scaffolds led to superior SC proliferation, attachment, and biological activity after seeding was shown under in vitro conditions (Li et al., 2015).

\section{EXPERIMENTAL CHITOSAN-BASED HYBRID STRATEGIES TO PROMOTE PERIPHERAL NERVE REGENERATION UNDER EXPERIMENTAL CONDITIONS}

The recent literature describes a variety of different types of hybrid strategies which aim to combine the advantages of chitosan with specific characteristics of other materials (see Table 1). The following section presents such chitosan hybrid strategies and discusses their potential role in reconstructive nerve surgery.

\section{Collagen}

Advantages of an adjustable biodegradation time as well as the relief of non-toxic components during biodegradation, make collagen a precious and well-investigated material supporting peripheral nerve healing (Deumens et al., 2010). Considering the accepted biomimicking concept for the treatment of peripheral nerve lesions, Nawrotek et al. (2016c) developed an epineuriummimicking chitosan conduit by a chemical composition of collagen, chitosan, and hyaluronic acid. Testing on mHippoE-18 mouse hippocampal cells, cell stimulation without cytotoxicity has been shown. As an alternative geometric design, one of the first chitosan-collagen films presented by Wei et al. (2003) showed promising results in a functional recovery for bridging peripheral nerve lesion of $5-10 \mathrm{~mm}$. Progress in tissue engineering further expanded the biomimicking approach for peripheral nerve reconstruction; thus Xiao combined a hybrid nerve guide based on collagen-chitosan and added an ArgGly-Asp (RGD) sequence, which is a well-known pattern and mostly used for supporting cell-adhesion abilities in tissue engineering. This led to superior results in histological and functional recovery compared to nerve conduits lacking an additional RGD sequence (Xiao et al., 2013). Recently, a collagen/chitosan nerve scaffold was introduced by Peng et al. (2018) fabricated by an "unidirectional freezing process" followed by further freeze-drying (Ding et al., 2010). On the basis of a collagen and chitosan suspension, this new scaffold was applied for bridging a peripheral nerve defect of $30 \mathrm{~mm}$ of the beagle's sciatic nerve. Based on the results of the electrophysiological assessment, retrograde tracing as well as histological evaluation, this collagen-chitosan nerve scaffold presented results equivalent to the ANT. If further experimental research confirms these identical recovery results via artificial conduits, such strategies will next be investigated in future clinical trials (Peng et al., 2018).

\section{Polyglycolic Acid (PGA)}

Polyglycolic acid has been widely used in the field of bridging peripheral nerve defects. Focusing on the reconstruction of extended- distance peripheral nerve defects PGA conduits filled with laminin-soaked collagen scaffolds or PGA-collagen fibers were found to promote axonal regeneration over a nerve lesion of up to $80 \mathrm{~mm}$ (Toba et al., 2002). Thus, it is reasonable to combine the beneficial effects of PGA with the potential of chitosan to further optimize the regeneration 


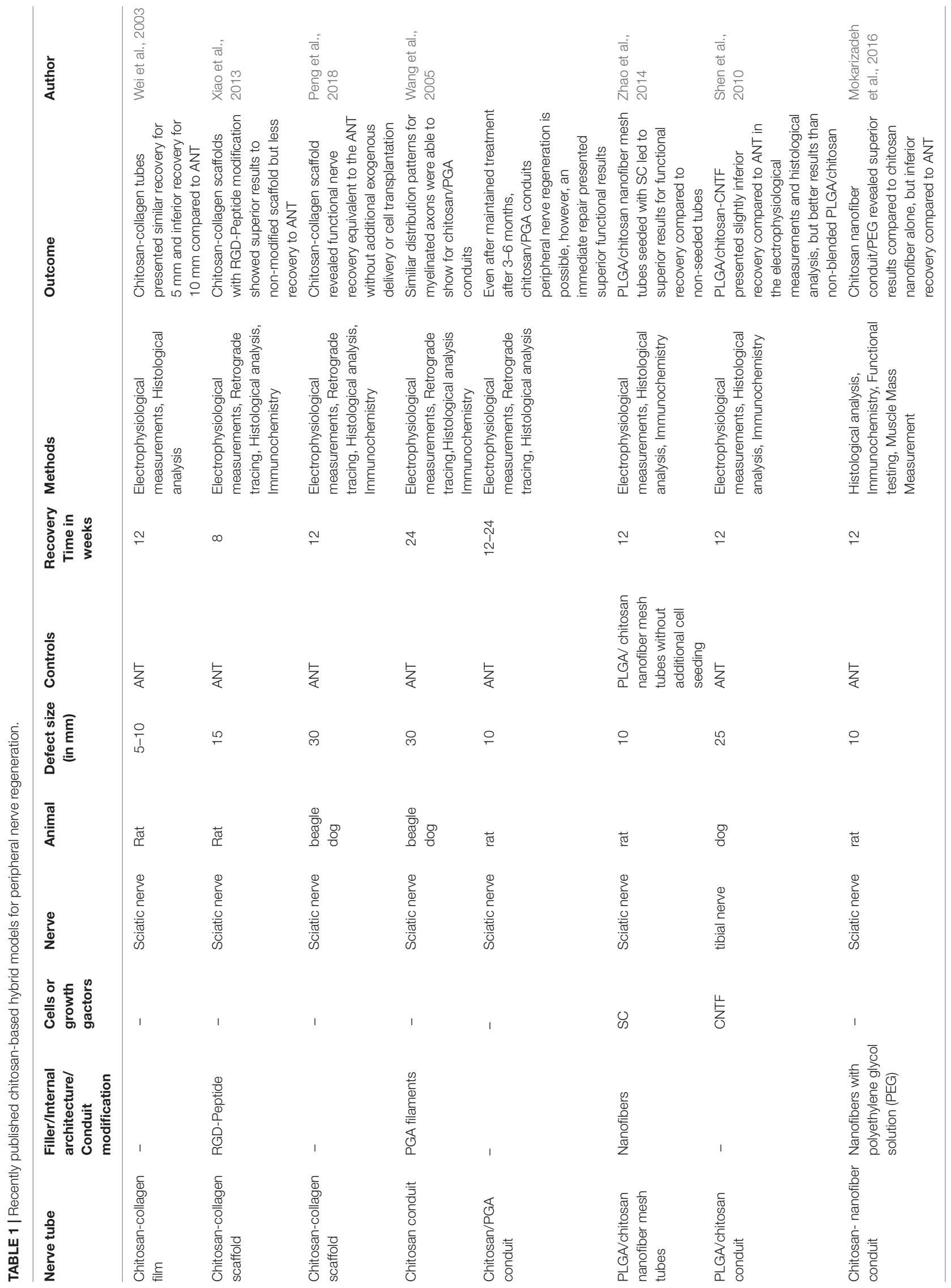


supporting conduit features. Therefore, Wang et al. (2005) developed a dual-component artificial nerve graft with an outer microporous conduit of chitosan and an inner layer of filaments PGA. In a beagle dog animal model with sciatic nerve lesion of $30 \mathrm{~mm}$ and a recovery interval of 6 months, the chitosan/PGA group showed a similar distribution pattern of myelinated fiber diameter compared to the ANT (Wang et al., 2005).

\section{Polylactic Acid (PLA) and Poly(Lactic-Co-glycolic Acid) (PLGA)}

The combination of chitosan and polylactide (CH-PLA) fibers presented a higher tensile strength and a lower tendency for swelling compared to chitosan fibers alone. The combination of a chitosan-based outer layer with an inner lining by (CH-PLA) fibers led to a guided axonal regeneration and thereby to the possibility to bridged long-distance peripheral nerve defects.

Furthermore, the CH-PLA fibers have been tested as a continuous release system of attached growth factors such as NGF and thereby induced a continuous outgrowth of PC12 cells as receptors for epidermal growth factor (EGF) both known to promote peripheral nerve regeneration (Huff and Guroff, 1979). Thus, CH-PLA fibers can be manufactured for gradient delivering not only for NGF but also other relevant growth factors by loading them into the alginate layers. Wu et al. emphasized the vast potential of these $\mathrm{CH}$ PLA fibers, especially for a guided axonal regeneration for long-gap nerve repair ( $\mathrm{Wu}$ et al., 2017). In line with this, Shen and colleagues bridged a peripheral nerve lesion of $25 \mathrm{~mm}$ of the canine tibial nerve in a dog animal model. Histological results illustrated that the PLGA/chitosan conduits were capable of providing peripheral nerve regeneration after 12 weeks. Results similar to the ANT can be reached by combining the PLGA/chitosan conduit with an additional coating of the ciliary neurotrophic factor (Shen et al., 2010). Moreover, the average maximum nerve fiber diameter and motor function have been improved by introducing dorsal root ganglion-derived SC to poly-(lactic-co-glycolic acid)/chitosan nerve scaffold for $10 \mathrm{~mm}$ sciatic nerve lesion in the rat (Zhao et al., 2014). However, materials based on PLA and PLGA suffer under a pH-decrease of the microenvironment during degradation and leading to an impaired of axonal regeneration (Deumens et al., 2010).

\section{Polyethylene Glycol}

Another promising hybrid approach is to combine chitosanbased nanofiber conduits with an additional filling of polyethylene glycol solution. In a $10 \mathrm{~mm}$ nerve defect of the rat's sciatic nerve, the superior functional outcome has been shown for animals treated with a substitute of the polyethylene solution. In contrast, functional recovery compared to the ANT showed clear inferior results for the experimental groups (Mokarizadeh et al., 2016). Furthermore, challenges of the chitosan in tissue engineering referring to the disadvantage in the processing of three-dimensional tubular forms without heating processing methods like extrusion or casting (Ao et al., 2006), were addressed by Nawrotek and colleagues by developing a tubular chitosan-carbon nanotube through the electrodeposition method. This conduit provided an excellent cell-adhesion, cell-proliferation, and cell-viability as well as structural stability for 28 days under in vivo conditions (Nawrotek et al., 2016c).

To sum up, hybrid concepts with chitosan have been well explored in literature, mostly for bridging peripheral nerve defects and led to promising results in peripheral nerve regeneration. Interestingly, the hybrid approach mainly revealed superior results of axonal recovery compared to concepts with chitosan alone. However, an exact differentiation of the effects of chitosan and the added material in a hybrid approach is not possible. Furthermore, hybrids concepts present the possibility of a tailored biodegradation as well as the embedding of growth factors or additional cell seeding related to the needs of peripheral nerve regeneration.

\section{ADDITIONAL CELL SEEDING COMBINED WITH CHITOSAN-BASED TREATMENT STRATEGIES}

Nerve regeneration through chitosan-based nerve tubes can be promoted by conduit enrichment via supportive molecules like laminin or growth factors as well as additional cell seeding (see Table 2).

\section{Additional Cell-Seeding With Schwann Cells (SC)}

The proliferative effect of chitosan on SC and inhibiting effect on the fibroblast growth has already been shown by Kuang et al. (1998). Thereby, chitosan has the potential to support the axonal regeneration by increasing the number of SC and may prevent scar tissue formation after peripheral nerve lesion (Kuang et al., 1998). Further investigations regarding biocompatibility among SC chitosan scaffolds or fibers were conducted by Yuan et al. (2004), leading to the conclusion that chitosan has an excellent neuroglial cell affinity with the ability to be an excellent cell carrier system after implantation. Chitosan membranes or fibers showed almost no cell toxicity for SC considering the results in the MTT Assay (Yuan et al., 2004).

As mentioned above, the DOA of the chitosan is crucial for the solvent characteristics and molar mass. Carvalho has shown that acetylation of $5 \%$ results in higher cell proliferation and phenotypic expression of SC-like cells compared to chitosan membranes with acetylation rates of $1 \%$ or $2 \%$ (Carvalho et al., 2017). The combination of SC with a chitosan nerve conduit substituted with self-fibroin filamentous fillers showed superior regeneration results compared to non-seeded chitosan conduits regarding the histological and functional outcome (Zhu et al., 2017).

\section{Additional Cell-Seeding With Bone Marrow Stromal Cells (BMSC)}

Bone marrow stromal cells seeded nerve conduits, in general, have shown to be a successful concept for bridging peripheral nerve defects and promoting axonal regeneration (Mimura et al., 


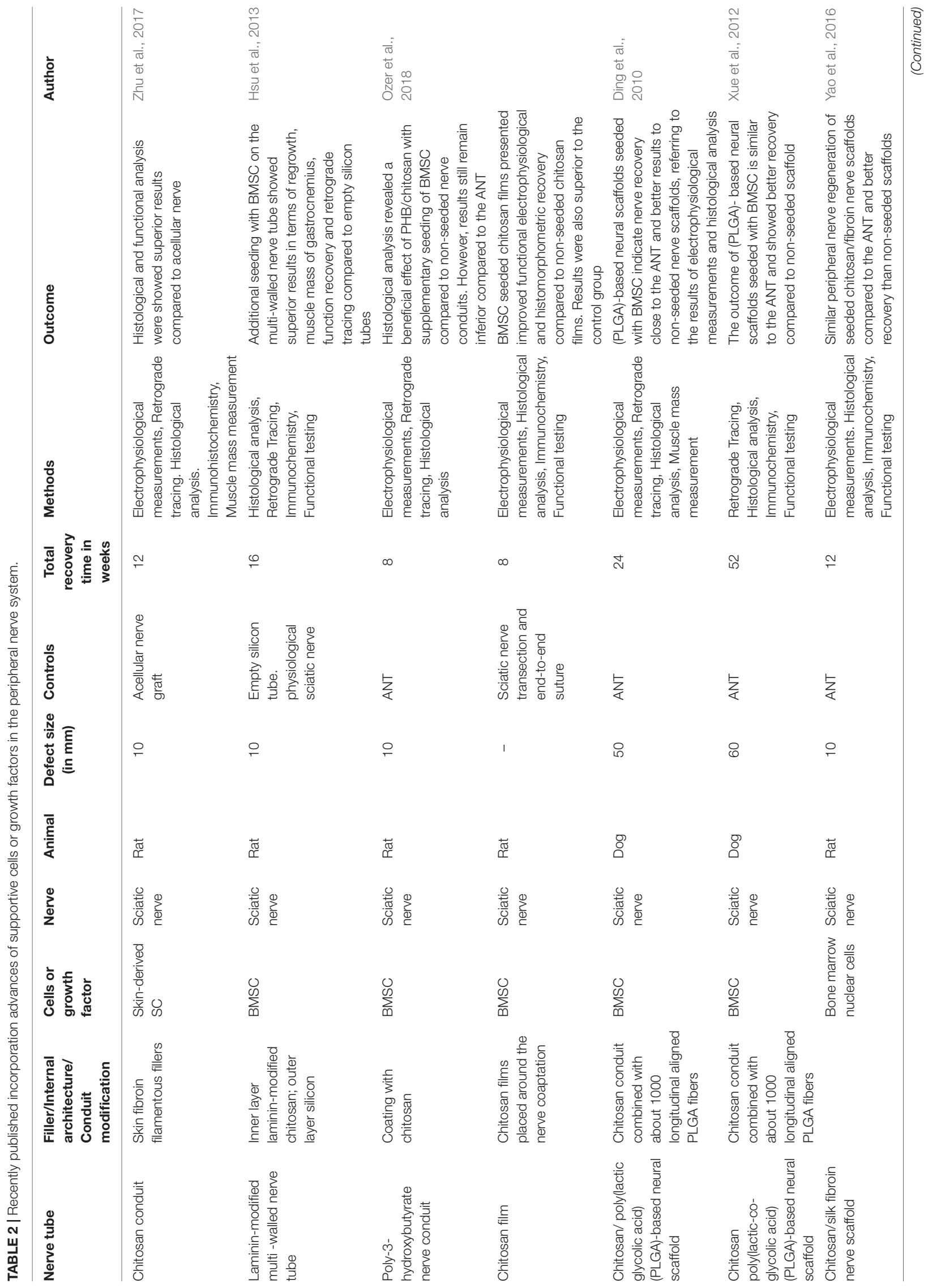




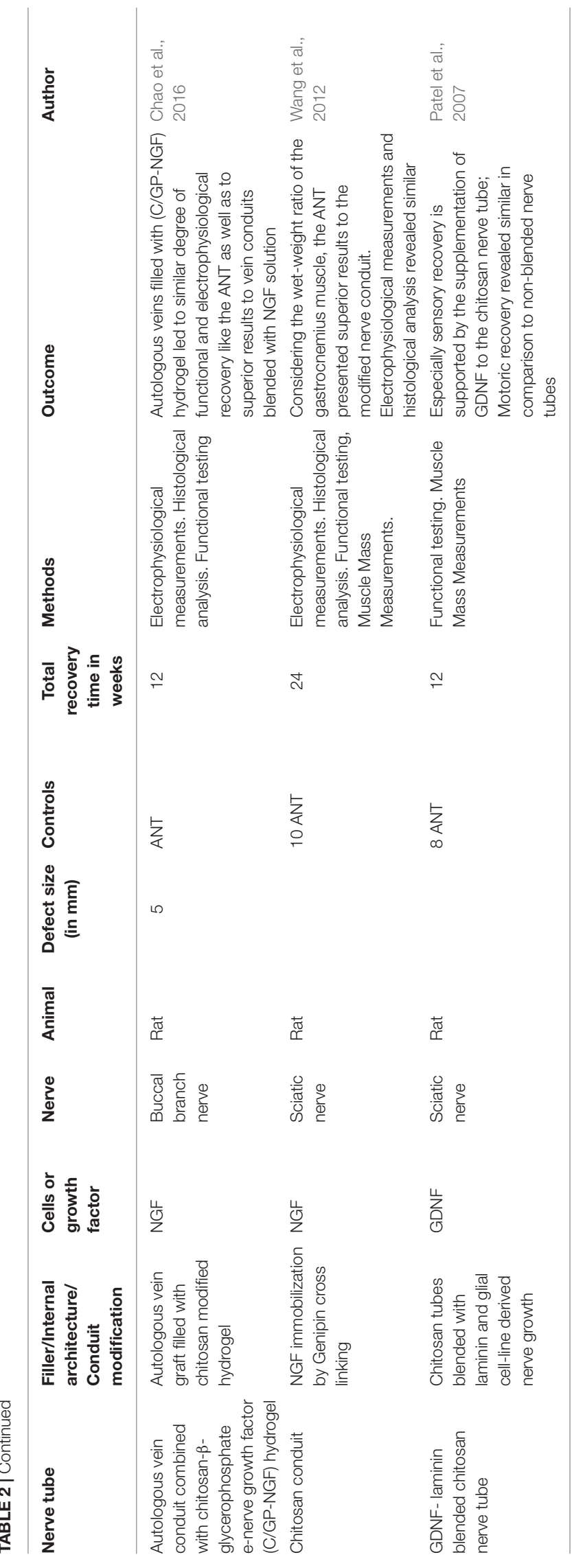

2004; Keilhoff et al., 2006; Boecker et al., 2015). Consequently, strategies to enhance peripheral nerve regeneration by BMSC seeded chitosan-based nerve guides has also been described. Hsu et al. (2013) published a two-component nerve tube with an inner layer based on laminin-modified chitosan and a siliconbased outer layer with a supplementary seeding of BMSC. As the control group, non-seeded laminin modified-chitosan scaffolds and empty silicone tubes have been utilized. After a regeneration period of 16 weeks and following histological investigations, hyperplasia tissue enriched with eosinophils and macrophages has been found. In this context, the importance of the inflammation after PNI, induced by these cells, was emphasized by the author (Hsu et al., 2013). In line with this, a chitosan-coated poly-3-hydroxybutyrate nerve conduit has been seeded with BMSC to bridge a $10 \mathrm{~mm}$ sciatic nerve lesion and led to superior results in functional recovery compared to non-seeded control group. However, the ANT showed still the best results of functional recovery (Ozer et al., 2018). Similar results have been assessed through Moattari et al. (2018) by exhibiting significant superior effects in which group? in the electromyography, nerve fiber density and myelinated axon diameter (Moattari et al., 2018). For bridging long distance peripheral nerve injuries of $50 \mathrm{~mm}$ or even $60 \mathrm{~mm}$, in a dog sciatic nerve, chitosan/poly(lacticco-glycolic acid) (PLGA)-based neural scaffolds have been combined with BMSC and evaluated by electrophysiology, retrograde tracing, and histology after recovery of 6 or 12 months. The results led to a nearly similar degree of functional regeneration compared to the ANT (Ding et al., 2010; Xue et al., 2012). Interestingly, Yao et al. (2016) was able to show, that Bone Marrow Mononuclear Cells joined with a chitosan/silk fibroin scaffold survived at least 2 weeks under in vivo conditions associated with an improved axonal guidance. Nearly similar results for functional recovery was accomplished compared to the ANT in the CatWalk gait analysis after 12 weeks of recovery (Yao et al., 2016). However, SC harvested during nerve surgery need long cultivation times to reach sufficient cell numbers for reimplantation and are associated with a loss of function related to donor's nerve.

Alternatively, BMSC can be harvested through bone marrow biopsy and revealed cell plasticity that can be adapted to the conditions of peripheral nerve regeneration (Keilhoff et al., 2006). However, the operation procedure is associated with surgical risks, like infection, bleeding, etc. Furthermore, the stability of differentiation has to be taken into account, BMSC have the ability to differentiate to SC-like cells under in vitro conditions but also have the capacity to re-differentiate to stem cell under the absence of the required factors, which is associated with a higher malignity degeneration rate (Gore et al., 2011).

Most current concepts of additional cell-seeding in peripheral nerve surgery remain as a proof principle because of the potential donor site morbidities, long lasting cultivation times before implantation and instability of cell differentiation (Boecker et al., 2015). Thereby, translational concepts with additional cell seeding based on chitosan are strongly restricted. 


\section{CHITOSAN-BASED DELIVERY SYSTEMS FOR GROWTH FACTORS}

In tissue engineered delivery systems the release kinetics of growth factors play a crucial role for axonal regeneration. Recently, a variety of different concepts have been published using chitosan as a delivery system for growth factors while peripheral nerve regeneration (see Table 2).

\section{Nerve Growth Factor (NGF)}

Pfister et al. (2008) were able to show a continuous delivery of bioactive NGF in low nanogram doses for 15 days. A nerve conduits of polyelectrolyte alginate/chitosan was coated with layers of poly(lactide-co-glycolide) (PLGA) to control the delivery of embedded NGF (Pfister et al., 2008). Moreover, the relevance of continuous delivery of NGF by using chitosan as carrying material and its synergetic effects have been marked by Chao et al. (2016). The combination of vein conduits filled with a chitosan- $\beta$-glycerophosphateNGF hydrogel presented superior histological, functional and electrophysiological recovery compared to non-filled vein conduits (Chao et al., 2016). This underlines the capacity of chitosan to be an excellent delivering system for growth factors related to the peripheral nerve regeneration.

Furthermore, chitosan nerve conduits with a supplementary immobilization of NGF via genipin cross-linking, were compared to the ANT for a $10 \mathrm{~mm}$-long sciatic nerve gap with 24 weeks recovery time. The crosslinked nerve conduit was superior compared to a non-crosslinked control but not to the ANT and led to inferior results in the electrophysiology and axon density compared to the gold standard. Thus, the real potential of additional NGF-application is hard to evaluate in this study design (Wang et al., 2012). The indication of chitosan tubes is not only limited to the treatment of PNI but can also be extended for nerve compression syndromes. Zhang et al. (2017) developed a chitosan-sericin scaffold for a continuous delivering of NGF. After application, a better functional recovery, as well as superior histological results has been demonstrated, probably caused by the beneficial effects of degradation products and the corresponding inducement of mRNA levels of GDNF, EGR2, NCAM as well as down-regulation levels of inflammatory genes (Zhang et al., 2017).

\section{Glial Cell Line-Derived Growth Factor (GDNF)}

The beneficial effects of GDNF on the peripheral nerve regeneration, like the support of motoneuron regeneration, acceleration of axonal regeneration and the prevention of muscle atrophy are known in the literature (Chen et al., 2001; Jubran and Widenfalk, 2003). Further developments in tissue engineering led to chitosan conduits enriched with laminin and GDNF. Non-prepared laminin-loaded chitosan tubes were compared to laminin-loaded chitosan tubes with supplementation of GDNF and used to bridge a nerve lesion of $10 \mathrm{~mm}$. An additional GDNF blending explicated a significant superior sensory recovery compared to unblended chitosan tubes (Patel et al., 2007).

\section{Fibroblast Growth Factor-2 (FGF-2)}

Fibroblast growth factor-2 is one of the 22 -member of the fibroblast growth factor family. In association with heparin or heparin sulfate proteoglycan, a variety of different effects has been reported including potent effects on angiogenesis and cell differentiation in the central nervous system. Chitosannanoparticles have been utilized as drug delivery systems for FGF-2. The chitosan scaffolds with incorporated FGF-2 microspheres reviewed superior results in cell survival and growth of neural stem cells compared to non-incorporated chitosan scaffolds under in vitro conditions (Woodbury and Ikezu, 2014). In line with this, chitosan scaffolds cross-linked with heparin and FGF-2 were assessed for cytocompatibility, attachment, and survival of neural stem cells (Skop et al., 2013). Alternatively, FGF-2 concentration can be increased by overpressing SC seeded in a chitosan hydrogel as an inner filling for a chitosan tube. Neural and Vascular (NVR) gel as inner filling has the obstacle to impair axonal outgrowth in a rat's sciatic nerve model. However, this challenge could be overcome by consistent delivery of FGF-2 of overexpressing SC and led to a significant extent in neurite outgrowth compared to free FGF-2 delivery or non-modified Neonatal Rat SC (Meyer et al., 2016b).

\section{Platelet-Derived Growth Factor (PDGF)}

Platelet-derived growth factor (PDGF) has been shown to support the migration of bone marrow stromal cells. Chitosan scaffolds have been loaded with chitosan-encapsulated PDGF microspheres and investigated for the biocompatibility of neural progenitor cells. Directional migration and growth of these cells were shown for scaffolds with additional PDGF incorporation. Chitosan microspheres underline their potential as a drug delivery system by releasing $52 \%$ of the PDGF in 4 weeks under in vitro conditions without a burst release (Chen et al., 2018). The beneficial effect of PDGF on neural stem progenitor cells by promoting the cell survival and cell differentiation to oligodendrocytes is described in the literature (Delayed transplantation of adult neural precursor cells promotes remyelination and functional neurological recovery after spinal cord injury; Endogenous and exogenous CNS derived stem/progenitor cell approaches for neurotrauma). In combination with chitosan channels and a continuous release of PDGF osmotic pump, neural stem progenitor cells have been significantly enhanced in cell survival under in vivo conditions (Guo et al., 2012).

\section{TRANSLATIONAL CONCEPTS OF CHITOSAN-BASED NERVE TUBES}

Yet, the application of chitosan-based nerve conduits beneath experimental research as translational concepts has not been explored sophisticatedly. Only a few studies have already implemented chitosan tubes in clinical practice and evaluated the functional outcome after application.

In first clinical treatments, the combination of a chitosan-PGA nerve conduit was utilized to bridge a long-distance defect of $35 \mathrm{~mm}$ of the median nerve distal to the bicep's aponeurosis. 
During a 3-year follow-up period sensory and motor function recovered satisfactorily to M4 and S3+ levels in testing. However, this case report need to be amended by further clinical studies to prove the clinical value of this nerve conduit (Fan et al., 2008). Similar results have been found by Gu et al. (2011) after bridging a $30 \mathrm{~mm}$ nerve defect of the median nerve with the same nerve conduit 2 years later. In June 2014, the first unaccompanied chitosan-based nerve conduit, named Reaxon ${ }^{\circledR}$ has been launched by Medovent GmbH (Mainz, Germany). Reaxon ${ }^{\circledR}$ was developed in accordance with the international standard DIN EN ISO 13485 and can be manufactured in different sizes depending on the diameter of the nerve. Nerve defects with a size up to $26 \mathrm{~mm}$ can be bridged in the clinical setting (Neubrech et al., 2016b). Furthermore, Reaxon ${ }^{\circledR}$ cannot only be used as tubulization-technique for bridging the peripheral nerve defects but also as a protector for the nerve coaptation after a tension-free epineural suture (Neubrech et al., 2016a).

Thus, besides several studies investigated beneficial effects of chitosan and its derivates in preclinical in vitro and in vivo models, the functional outcome after traumatic sensory nerve lesions can significantly be enhanced by a supplementary use of Reaxon ${ }^{\circledR}$ as protection for the epineural suture in daily clinical routine (see Figure 2). In a double-blinded, randomized, prospective clinical trial, after a 6-months follow-up, a $6.3 \mathrm{~mm}$ two-point-discrimination has been found for patients treated with the additional chitosan-based conduit compared to the control group with two-point discrimination of $8 \mathrm{~mm}$. This significant enhancement of the tactile gnosis is a relevant parameter for functional recovery of the hand (Neubrech et al., 2018). The capability of Reaxon ${ }^{\circledR}$ has been further investigated by Ronchi et al. by combining the chitosan tube with skeletal muscle fibers of the pectoralis muscle to bridge a $10 \mathrm{~mm}$ nerve lesion of the median nerve. Biomolecular analysis has shown an increased production and release of Neuregulin, as a key factor for SC survival and vitality. However, functional recovery and morphometric analyses presented no significant differences compared to hollow chitosan tubes. The author considered, beneficial effects of an inner lining by an additional muscle application is more indicated for nerve lesion of an extended distance than for a nerve lesion size of $10 \mathrm{~mm}$ in humans (Ronchi et al., 2018).

In the future, the possible clinical application of Chitosan in the field of peripheral nerve surgery is vast and can be used for bridging peripheral nerve lesion, protecting the epineural coaptation or even for neuroma prevention.

Referring to the findings of Marcol et al. (2011), new developments in material science led to chitosan-based nerve caps, which may have the capacity to limit neuroma formation by combining a mechanical obstacle with an additional materialrelated biochemical barrier for unguided axonal sprouting. Based on the material properties, recent material science concepts, such as chitosan gel, film or microcrystals, for an easier application of the material is also possible.
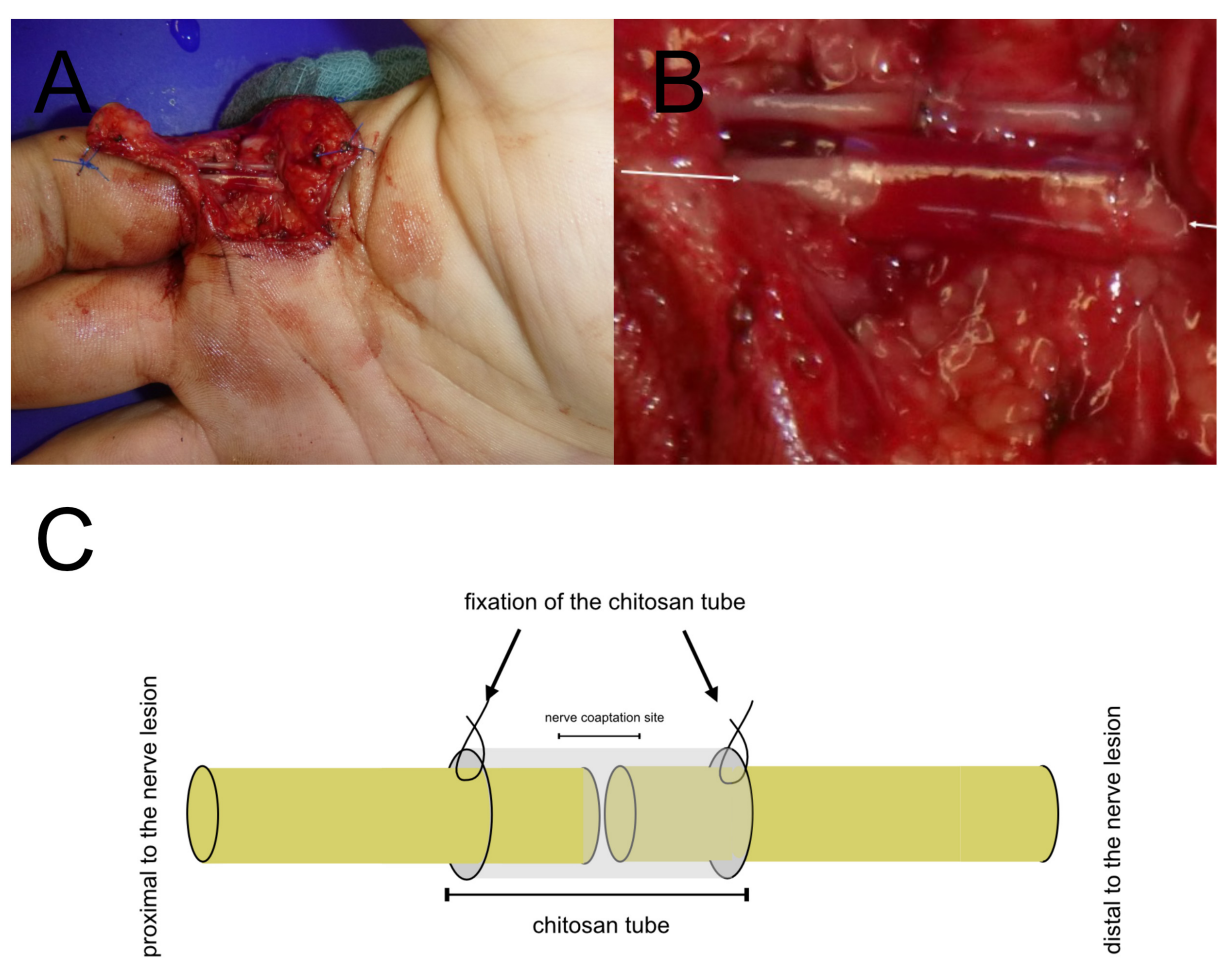

FIGURE 2 | Translational Concepts in daily clinical practice. Chitosan nerve tube protects the epineural nerve coaptation (A). Magnification of the chitosan-based nerve tube for covering the epineural suture of the third proper palmar digital (B). Protection of the epineural nerve coaptation by a chitosan-based nerve tube in a model $\mathbf{( C )}$. (A,B) has been taken during clinical routine care. 
In conclusion, the capability of chitosan as a sophisticated partner in the peripheral nerve regeneration has been explored in several in vitro and in vivo experimental approaches. Not only the cell biocompatibility of chitosan on neural cells was shown but also beneficial effects on the differentiation and proliferation on SC as well as BMSC. Moreover, COS, as the metabolite of chitosan during biodegradation, is a neuroprotective agent during peripheral nerve regeneration and a direct stimulator for SC. Under in vivo conditions, chitosan was able to bridge peripheral nerve defects up to $60 \mathrm{~mm}$ in combination with a chitosan/poly(lactic-co-glycolic acid) (PLGA)-based neural scaffold combined with BMSC. First human trials in 2011 presented sensory recovery after chitosan tube implantation for a median nerve lesion. Recently, the first chitosan-based nerve guide was launched for clinical application and led to superior sensory recovery by using it as a biochemical protector for the site of the epineural nerve coaptation. However, given the only few human clinical trials investigating chitosan conduits, the effect on the outcome following all kinds of nerve surgery (decompression, defect reconstruction, and neuroma prevention) and thereby its potential value have to be evaluated. However, considering the first results of clinical trials and previous in vitro and in vivo experiments, chitosan has an immense potential to be a valuable partner for the peripheral nerve surgeon in the future.

\section{CONCLUSION}

The relevance and application of chitosan in the field of peripheral nerve surgery are tremendous and can principally be separated between the support axonal regeneration by giving mechanical guidance and stability (as chitosan tube, inner filling or epineural suture protector) or being used as drug delivery system.

Chitosan has good biocompatibility of the peripheral nervous system, and mechanical properties make custommade biodegradation possible. To overcome mechanical instability in a variety of different approaches in tissue engineering reaching from chitosan microspheres to chitosan hydrogel have been explored. Especially hybrid-models based on chitosan can be tailored to the demands of nerve

\section{REFERENCES}

Ao, Q., Wang, A., Cao, W., Zhang, L., Kong, L., He, Q., et al. (2006). Manufacture of multimicrotubule chitosan nerve conduits with novel molds and characterization in vitro. J. Biomed. Mater. Res. A 77, 11-18. doi: 10.1002/ jbm.a.30593

Boecker, A. H., van Neerven, S. G. A., Scheffel, J., Tank, J., Altinova, H., Seidensticker, K., et al. (2015). Pre-differentiation of mesenchymal stromal cells in combination with a microstructured nerve guide supports peripheral nerve regeneration in the rat sciatic nerve model. Eur. J. Neurosci. 43, 404-416. doi: 10.1111/ejn.13052

Bozkurt, A., Lassner, F., O’Dey, D., Deumens, R., Böcker, A., Schwendt, T., et al. (2012). The role of microstructured and interconnected pore channels in a collagen-based nerve guide on axonal regeneration in peripheral nerves. Biomaterials 33, 1363-1375. doi: 10.1016/j.biomaterials.2011. 10.069 recovery and showed promising results on all levels of peripheral nerve regeneration. In translational concepts, chitosan has been generally proven to support functional recovery, however, the clinical evidence is limited to a small number of studies yet. Future investigations should focus on the clinical outcome after application of chitosan as a drug delivery system or mechanical guidance/protection after peripheral nerve injury.

\section{DISCLOSURES}

Referring to Reaxon mentioned in this review, the study "Enhancing the Outcome of Traumatic Sensory Nerve Lesions of the Hand by Additional Use of a Chitosan Nerve Tube in Primary Nerve Repair: A Randomized Controlled Bicentric Trial" was sponsored by the Medovent. The study was conceived and designed before seeking financial support. Medovent was excluded from any aspect, conduct, analysis, write-up or publication of the trial. None of the authors has any personal financial related to Medovent. None of the authors has accepted compensations, fees, funding, or salary from Medovent.

\section{AUTHOR CONTRIBUTIONS}

$\mathrm{AB}$ contributed to the concept and design of the review, performed literature research, and involved in drafting and critically revising the manuscript. SD and UK involved in drafting and critically revising the manuscript. LH contributed to the concept and design of the review and involved in drafting and critically revising the manuscript. All authors read and approved the final manuscript.

\section{FUNDING}

We acknowledge financial support by Deutsche Forschungsgeme inschaft within the funding programme Open Access Publishing, by the Baden-Württemberg Ministry of Science, Research and the Arts and by Ruprecht-Karls-Universität Heidelberg.

Carvalho, C. R., López-Cebral, R., Silva-Correia, J., Silva, J. M., Mano, J. F., Silva, T. H., et al. (2017). Investigation of cell adhesion in chitosan membranes for peripheral nerve regeneration. Mater. Sci. Eng. C 71, 1122-1134. doi: 10.1016/j. msec.2016.11.100

Chao, X., Fan, Z., Han, Y., Wang, Y., Li, J., Chai, R., et al. (2015). Effects of local application of methylprednisolone delivered by the C/GP-hydrogel on the recovery of facial nerves. Acta Otolaryngol. 135, 1178-1184.

Chao, X., Xu, L., Li, J., Han, Y., Li, X., Mao, Y., et al. (2016). Facilitation of facial nerve regeneration using chitosan- $\beta$-glycerophosphate-nerve growth factor hydrogel. Acta Otolaryngol. 136, 585-591. doi: 10.3109/00016489.2015.1136432

Chatelet, C., Damour, O., and Domard, A. (2001). Influence of the degree of acetylation on some biological properties of chitosan films. Biomaterials 22, 261-268. doi: 10.1016/S0142-9612(00)00183-6

Chen, X., Xu, M. L., Wang, C. N., Zhang, L. Z., Zhao, Y. H., Zhu, C. L., et al. (2018). A partition-type tubular scaffold loaded with PDGF-releasing microspheres 
for spinal cord repair facilitates the directional migration and growth of cells. Neural Regen. Res. 13, 1231-1240. doi: 10.4103/1673-5374.235061

Chen, Z.-Y., Chai, Y.-F., Cao, L., Lu, C.-L., and He, C. (2001). Glial cell linederived neurotrophic factor enhances axonal regeneration following sciatic nerve transection in adult rats. Brain Res. 902, 272-276. doi: 10.1016/S00068993(01)02395-2

Cheng, M., Gong, K., Li, J., Gong, Y., Zhao, N., Zhang, X., et al. (2004). Surface modification and characterization of chitosan film blended with poly-L-lysine. J. Biomater. Appl. 19, 59-75. doi: 10.1177/0885328204043450

Crompton, K. E., Goud, J. D., Bellamkonda, R. V., Gengenbach, T. R., Finkelstein, D. I., Horne, M. K., et al. (2007). Polylysine-functionalised thermoresponsive chitosan hydrogel for neural tissue engineering. Biomaterials 28, 441-449. doi: 10.1016/J.BIOMATERIALS.2006.08.044

Davis, L., and Perret, G. (1946). Homogenous grafts in the repair of peripheral nerve lesions in man. Proc. Inst. Med. Chic. 16:167.

Desai, K. G. H., and Park, H. J. (2005). Preparation of cross-linked chitosan microspheres by spray drying: effect of cross-linking agent on the properties of spray dried microspheres. J. Microencapsul. 22, 377-395. doi: 10.1080/ 02652040500100139

Deumens, R., Bozkurt, A., Meek, M. F., Marcus, M. A., Joosten, E. A., Weis, J., et al. (2010). Repairing injured peripheral nerves: bridging the gap. Prog. Neurobiol. 92, 245-276. doi: 10.1016/j.pneurobio.2010.10.002

Ding, F., Wu, J., Yang, Y., Hu, W., Zhu, Q., Tang, X., et al. (2010). Use of tissue-engineered nerve grafts consisting of a chitosan/poly(lactic- co -glycolic acid)-based scaffold included with bone marrow mesenchymal cells for bridging 50-mm dog sciatic nerve gaps. Tissue Eng. Part A 16, 3779-3790. doi: 10.1089/ ten.tea.2010.0299

Du, J., Liu, J., Yao, S., Mao, H., Peng, J., Sun, X., et al. (2017). Prompt peripheral nerve regeneration induced by a hierarchically aligned fibrin nanofiber hydrogel. Acta Biomater. 55, 296-309. doi: 10.1016/j.actbio.2017.04.010

Fan, W., Gu, J., Hu, W., Deng, A., Ma, Y., Liu, J., et al. (2008). Repairing a 35mm-long median nerve defect with a chitosan/PGA artificial nerve graft in the human: a case study. Microsurgery 28, 238-242. doi: 10.1002/micr.20488

Fregnan, F., Ciglieri, E., Tos, P., Crosio, A., Ciardelli, G., Ruini, F., et al. (2016). Chitosan crosslinked flat scaffolds for peripheral nerve regeneration. Biomed. Mater. 11:045010. doi: 10.1088/1748-6041/11/4/045010

Freier, T., Koh, H. S., Kazazian, K., and Shoichet, M. S. (2005a). Controlling cell adhesion and degradation of chitosan films by $\mathrm{N}$-acetylation. Biomaterials 26 , 5872-5878. doi: 10.1016/j.biomaterials.2005.02.033

Freier, T., Montenegro, R., Shan Koh, H., and Shoichet, M. S. (2005b). Chitin-based tubes for tissue engineering in the nervous system. Biomaterials 26, 4624-4632. doi: 10.1016/j.biomaterials.2004.11.040

Gong, Y., Gong, L., Gu, X., and Ding, F. (2009). Chitooligosaccharides promote peripheral nerve regeneration in a rabbit common peroneal nerve crush injury model. Microsurgery 29, 650-656. doi: 10.1002/micr.20686

Gore, A., Li, Z., Fung, H.-L. L., Young, J. E., Agarwal, S., Antosiewicz-Bourget, J., et al. (2011). Somatic coding mutations in human induced pluripotent stem cells. Nature 470, 63-67. doi: 10.1038/nature09805.Somatic

Gu, X., Ding, F., Yang, Y., and Liu, J. (2011). Construction of tissue engineered nerve grafts and their application in peripheral nerve regeneration. Prog. Neurobiol. 93, 204-230. doi: 10.1016/j.pneurobio.2010.11.002

Guo, Q., Liu, C., Hai, B., Ma, T., Zhang, W., Tan, J., et al. (2018). Chitosan conduits filled with simvastatin/Pluronic F-127 hydrogel promote peripheral nerve regeneration in rats. J. Biomed. Mater. Res. Part B Appl. Biomater. 106, 787-799. doi: 10.1002/jbm.b.33890

Guo, X., Zahir, T., Mothe, A., Shoichet, M. S., Morshead, C. M., Katayama, Y., et al. (2012). The effect of growth factors and soluble Nogo-66 receptor protein on transplanted neural stem/progenitor survival and axonal regeneration after complete transection of rat spinal cord. Cell Transplant. 21, 1177-1197. doi: 10.3727/096368911X612503

Haastert-Talini, K., Geuna, S., Dahlin, L. B., Meyer, C., Stenberg, L., Freier, T., et al. (2013). Chitosan tubes of varying degrees of acetylation for bridging peripheral nerve defects. Biomaterials 34, 9886-9904. doi: 10.1016/j.biomaterials.2013.08. 074

Haipeng, G., Yinghui, Z., Jianchun, L., Yandao, G., Nanming, Z., and Xiufang, Z. (2000). Studies on nerve cell affinity of chitosan-derived materials. J. Biomed. Mater. Res. 52, 285-295.
Hao, C., Wang, W., Wang, S., Zhang, L., and Guo, Y. (2017). An overview of the protective effects of chitosan and acetylated chitosan oligosaccharides against neuronal disorders. Mar. Drugs 15:E89. doi: 10.3390/md15040089

He, B., Tao, H.-Y., and Liu, S.-Q. (2014). Neuroprotective effects of carboxymethylated chitosan on hydrogen peroxide induced apoptosis in Schwann cells. Eur. J. Pharmacol. 740, 127-134. doi: 10.1016/j.ejphar.2014.07. 008

Hsu, S. H., Kuo, W. C., Chen, Y. T., Yen, C. T., Chen, Y. F., Chen, K. S., et al. (2013). New nerve regeneration strategy combining laminin-coated chitosan conduits and stem cell therapy. Acta Biomater. 9, 6606-6615. doi: 10.1016/j.actbio.2013. 01.025

Huang, H.-C., Hong, L., Chang, P., Zhang, J., Lu, S.-Y., Zheng, B.-W., et al. (2015). Chitooligosaccharides attenuate $\mathrm{Cu} 2+$-induced cellular oxidative damage and cell apoptosis involving Nrf2 activation. Neurotox. Res. 27, 411-420. doi: 10.1007/s12640-014-9512-x

Huang, Y.-C., Huang, C.-C., Huang, Y.-Y., and Chen, K.-S. (2007). Surface modification and characterization of chitosan or PLGA membrane with laminin by chemical and oxygen plasma treatment for neural regeneration. J. Biomed. Mater. Res. A 82, 842-851. doi: 10.1002/jbm.a.31036

Huff, K. R., and Guroff, G. (1979). Nerve growth factor-induced reduction in epidermal growth factor responsiveness and epidermal growth factor receptors in PC12 cells: an aspect of cell differentiation. Biochem. Biophys. Res. Commun. 89, 175-180. doi: 10.1016/0006-291X(79)90960-4

Inada, Y., Hosoi, H., Yamashita, A., Morimoto, S., Tatsumi, H., Notazawa, S., et al. (2007). Regeneration of peripheral motor nerve gaps with a polyglycolic acid-collagen tube: technical case report. Neurosurgery 61, E1105-E1107. doi: 10.1227/01.neu.0000303210.45983.97

Itoh, S., Matsuda, A., Kobayashi, H., Ichinose, S., Shinomiya, K., and Tanaka, J. (2005). Effects of a laminin peptide (YIGSR) immobilized on crab-tendon chitosan tubes on nerve regeneration. J. Biomed. Mater. Res. B Appl. Biomater. 73, 375-382. doi: 10.1002/jbm.b.30224

Itoh, S., Suzuki, M., Yamaguchi, I., Takakuda, K., Kobayashi, H., Shinomiya, K., et al. (2003). Development of a nerve scaffold using a tendon chitosan tube. Artif. Organs 27, 1079-1088. doi: 10.1111/j.1525-1594.2003.07208.x

Jubran, M., and Widenfalk, J. (2003). Repair of peripheral nerve transections with fibrin sealant containing neurotrophic factors. Exp. Neurol. 181, 204-212. doi: 10.1016/S0014-4886(03)00041-4

Kato, K., Utani, A., Suzuki, N., Mochizuki, M., Yamada, M., Nishi, N., et al. (2002). Identification of neurite outgrowth promoting sites on the laminin alpha 3 chain G domain. Biochemistry 41, 10747-10753. doi: 10.1021/ bi020180k

Keilhoff, G., Goihl, A., Langnase, K., Fansa, H., Wolf, G., Langnäse, K., et al. (2006). Transdifferentiation of mesenchymal stem cells into schwann cell-like myelinating cells. Eur. J. Cell Biol. 85, 11-24. doi: 10.1016/j.ejcb.2005.09.021

Kim, S., Nimni, M. E., Yang, Z., and Han, B. (2005). Chitosan/gelatin-based films crosslinked by proanthocyanidin. J. Biomed. Mater. Res. B Appl. Biomater. 75, 442-450. doi: $10.1002 / \mathrm{jbm}$. b. 30324

Kuang, Y., Hou, C., and Gou, S. (1998). [Experimental study of the effect on growth of Schwann cell from chitin and chitosan in vitro]. Zhongguo Xiu Fu Chong Jian Wai Ke Za Zhi 12, 90-93.

Li, G., Zhang, L., and Yang, Y. (2015). Tailoring of chitosan scaffolds with heparin and $\gamma$-aminopropyltriethoxysilane for promoting peripheral nerve regeneration. Colloids Surf. B Biointerfaces 134, 413-422. doi: 10.1016/j. colsurfb.2015.07.012

Liu, H., Wen, W., Hu, M., Bi, W., Chen, L., Liu, S., et al. (2013). Chitosan conduits combined with nerve growth factor microspheres repair facial nerve defects. Neural Regen. Res. 8, 3139-3147. doi: 10.3969/j.issn.1673-5374.2013.33.008

Lundborg, G. (2004). Alternatives to autologous nerve grafts. Handchir. Mikrochir. Plast. Chir. 36, 1-7. doi: 10.1055/s-2004-820870

Madihally, S. V., and Matthew, H. W. (1999). Porous chitosan scaffolds for tissue engineering. Biomaterials 20, 1133-1142. doi: 10.1016/S0142-9612(99)00011-3

Marcol, W., Larysz-Brysz, M., Kucharska, M., Niekraszewicz, A., Slusarczyk, W., Kotulska, K., et al. (2011). Reduction of post-traumatic neuroma and epineural scar formation in rat sciatic nerve by application of microcrystallic chitosan. Microsurgery 31, 642-649. doi: 10.1002/micr.20945

Martín-López, E., Alonso, F. R., Nieto-Díaz, M., and Nieto-Sampedro, M. (2012). Chitosan, gelatin and poly(L-Lysine) polyelectrolyte-based scaffolds and films 
for neural tissue engineering. J. Biomater. Sci. Polym. Ed. 23, 207-232. doi: $10.1163 / 092050610 X 546426$

Meek, M. F., and Coert, J. H. (2008). US Food and Drug Administration /Conformit Europe- approved absorbable nerve conduits for clinical repair of peripheral and cranial nerves. Ann. Plast. Surg. 60, 466-472. doi: 10.1097/SAP. 0b013e31804d441c

Mehrshad, A., Shahraki, M., and Ehteshamfar, S. (2017). Local administration of methylprednisolone laden hydrogel enhances functional recovery of transected sciatic nerve in rat. Bull. Emerg. Trauma 5, 231-239. doi: 10.18869/acadpub. beat.5.4.509

Meyer, C., Stenberg, L., Gonzalez-Perez, F., Wrobel, S., Ronchi, G., Udina, E., et al. (2016a). Chitosan-film enhanced chitosan nerve guides for long-distance regeneration of peripheral nerves. Biomaterials 76, 33-51. doi: 10.1016/j. biomaterials.2015.10.040

Meyer, C., Wrobel, S., Raimondo, S., Rochkind, S., Heimann, C., Shahar, A., et al. (2016b). Peripheral nerve regeneration through hydrogel-enriched chitosan conduits containing engineered schwann cells for drug delivery. Cell Transplant. 25, 159-182. doi: 10.3727/096368915X688010

Mimura, T., Dezawa, M., Kanno, H., Sawada, H., and Yamamoto, I. (2004). Peripheral nerve regeneration by transplantation of bone marrow stromal cellderived Schwann cells in adult rats. J. Neurosurg. 101, 806-812. doi: 10.3171/ jns.2004.101.5.0806

Moattari, M., Kouchesfehani, H. M., Kaka, G., Sadraie, S. H., Naghdi, M., and Mansouri, K. (2018). Chitosan-film associated with mesenchymal stem cells enhanced regeneration of peripheral nerves: a rat sciatic nerve model. J. Chem. Neuroanat. 88, 46-54. doi: 10.1016/j.jchemneu.2017.10.003

Mokarizadeh, A., Mehrshad, A., and Mohammadi, R. (2016). Local polyethylene glycol in combination with chitosan based hybrid nanofiber conduit accelerates transected peripheral nerve regeneration. J. Invest. Surg. 29, 167-174. doi: 10. 3109/08941939.2015.1098758

Nawrotek, K., Tylman, M., Decherchi, P., Marqueste, T., Rudnicka, K., Gatkowska, J., et al. (2016a). Assessment of degradation and biocompatibility of electrodeposited chitosan and chitosan-carbon nanotube tubular implants. J. Biomed. Mater. Res. A 104, 2701-2711. doi: 10.1002/jbm.a.35812

Nawrotek, K., Tylman, M., Rudnicka, K., Balcerzak, J., and Kamiński, K. (2016b). Chitosan-based hydrogel implants enriched with calcium ions intended for peripheral nervous tissue regeneration. Carbohydr. Polym. 136, 764-771. doi: 10.1016/j.carbpol.2015.09.105

Nawrotek, K., Tylman, M., Rudnicka, K., Gatkowska, J., and Wieczorek, M. (2016c). Epineurium-mimicking chitosan conduits for peripheral nervous tissue engineering. Carbohydr. Polym. 152, 119-128. doi: 10.1016/j.carbpol. 2016.07.002

Neubrech, F., Heider, S., Harhaus, L., Bickert, B., Kneser, U., and Kremer, T. (2016a). Chitosan nerve tube for primary repair of traumatic sensory nerve lesions of the hand without a gap: study protocol for a randomized controlled trial. Trials 17:48. doi: 10.1186/s13063-015-1148-5

Neubrech, F., Heider, S., Otte, M., Hirche, C., Kneser, U., and Kremer, T. (2016b). Nerve tubes for the repair of traumatic sensory nerve lesions of the hand: review and planning study for a randomised controlled multicentre trial. Handchir. Mikrochir. Plast. Chir. 48, 148-154. doi: 10.1186/s13063-0151148-5

Neubrech, F., Sauerbier, M., Moll, W., Seegmüller, J., Heider, S., Harhaus, L., et al. (2018). Enhancing the outcome of traumatic sensory nerve lesions of the hand by additional use of a chitosan nerve tube in primary nerve repair. Plast. Reconstr. Surg. 142, 415-424. doi: 10.1097/PRS.0000000000004574

Nicholson, B., and Verma, S. (2004). Comorbidities in chronic neuropathic pain. Pain Med. 5(Suppl. 1), S9-S27. doi: 10.1111/j.1526-4637.2004.04019.x

Noble, J., Munro, C. A., Prasad, V. S., and Midha, R. (1998). Analysis of upper and lower extremity peripheral nerve injuries in a population of patients with multiple injuries. J. Trauma 45, 116-122. doi: 10.1097/00005373-19980700000025

Ozer, H., Bozkurt, H., Bozkurt, G., and Demirbilek, M. (2018). Regenerative potential of chitosan-coated poly-3-hydroxybutyrate conduits seeded with mesenchymal stem cells in a rat sciatic nerve injury model. Int. J. Neurosci. 128, 828-834. doi: 10.1080/00207454.2018.1435536

Pangestuti, R., and Kim, S.-K. (2010). Neuroprotective properties of chitosan and its derivatives. Mar. Drugs 8, 2117-2128. doi: 10.3390/md8072117
Patel, M., Mao, L., Wu, B., and VandeVord, P. J. (2007). GDNF-chitosan blended nerve guides: a functional study. J. Tissue Eng. Regen. Med. 1, 360-367. doi: $10.1002 /$ term. 44

Pavinatto, F. J., Caseli, L., and Oliveira, O. N. (2010). Chitosan in nanostructured thin films. Biomacromolecules 11, 1897-1908. doi: 10.1021/bm1004838

Peng, Y., Li, K.-Y. Y., Chen, Y.-F. F., Li, X.-J. J., Zhu, S., Zhang, Z.-Y. Y., et al. (2018). Beagle sciatic nerve regeneration across a $30 \mathrm{~mm}$ defect bridged by chitosan/PGA artificial nerve grafts. Injury 49, 1477-1484. doi: 10.1016/j.injury. 2018.03.023

Pfister, L. A., Alther, E., Papaloïzos, M., Merkle, H. P., and Gander, B. (2008). Controlled nerve growth factor release from multi-ply alginate/chitosan-based nerve conduits. Eur. J. Pharm. Biopharm. 69, 563-572. doi: 10.1016/j.ejpb.2008. 01.014

Rickett, T. A., Amoozgar, Z., Tuchek, C. A., Park, J., Yeo, Y., and Shi, R. (2011). Rapidly photo-cross-linkable chitosan hydrogel for peripheral neurosurgeries. Biomacromolecules 12, 57-65. doi: 10.1021/bm101004r

Ronchi, G., Fornasari, B. E., Crosio, A., Budau, C. A., Tos, P., Perroteau, I., et al. (2018). Chitosan tubes enriched with fresh skeletal muscle fibers for primary nerve repair. Biomed Res. Int. 2018:9175248. doi: 10.1155/2018/ 9175248

Schmidt, C. E., and Leach, J. B. (2003). Neural tissue engineering: strategies for repair and regeneration. Annu. Rev. Biomed. Eng. 5, 293-347. doi: 10.1146/ annurev.bioeng.5.011303.120731

Schneider, A., Vodouhe, C., Richert, L., Francius, G., Le Guen, E., Schaaf, P., et al. (2007). Multifunctional polyelectrolyte multilayer films: combining mechanical resistance, biodegradability, and bioactivity. Biomacromolecules 8, 139-145. doi: 10.1021/bm060765k

Shapira, Y., Tolmasov, M., Nissan, M., Reider, E., Koren, A., Biron, T., et al. (2016). Comparison of results between chitosan hollow tube and autologous nerve graft in reconstruction of peripheral nerve defect: an experimental study. Microsurgery 36, 664-671. doi: 10.1002/micr.22418

Shen, H., Shen, Z.-L., Zhang, P.-H., Chen, N.-L., Wang, Y.-C., Zhang, Z.-F., et al. (2010). Ciliary neurotrophic factor-coated polylactic-polyglycolic acid chitosan nerve conduit promotes peripheral nerve regeneration in canine tibial nerve defect repair. J. Biomed. Mater. Res. B Appl. Biomater. 95, 161-170. doi: 10.1002/ jbm.b.31696

Silva, J. M., Duarte, A. R. C., Custódio, C. A., Sher, P., Neto, A. I., Pinho, A. C. M., et al. (2014). Nanostructured hollow tubes based on chitosan and alginate multilayers. Adv. Healthc. Mater. 3, 433-440. doi: 10.1002/adhm.201300265

Skop, N. B., Calderon, F., Levison, S. W., Gandhi, C. D., and Cho, C. H. (2013). Heparin crosslinked chitosan microspheres for the delivery of neural stem cells and growth factors for central nervous system repair. Acta Biomater. 9, 6834-6843. doi: 10.1016/j.actbio.2013.02.043

Stenberg, L., Kodama, A., Lindwall-Blom, C., and Dahlin, L. B. (2016). Nerve regeneration in chitosan conduits and in autologous nerve grafts in healthy and in type 2 diabetic Goto-Kakizaki rats. Eur. J. Neurosci. 43, 463-473. doi: 10.1111/ejn.13068

Stößel, M., Wildhagen, V. M., Helmecke, O., Metzen, J., Pfund, C. B., Freier, T., et al. (2018). Comparative evaluation of chitosan nerve guides with regular or increased bendability for acute and delayed peripheral nerve repair: a comprehensive comparison with autologous nerve grafts and muscle-in-vein grafts. Anat. Rec. 301, 1697-1713. doi: 10.1002/ar.23847

Struszczyk, M. H. (2002). Chitin and chitosan: part III. Some aspects of biodegradation and bioactivity. Polimery 47, 619-629. doi: 10.14314/polimery. 2002.619

Suzuki, M., Itoh, S., Yamaguchi, I., Takakuda, K., Kobayashi, H., Shinomiya, K., et al. (2003). Tendon chitosan tubes covalently coupled with synthesized laminin peptides facilitate nerve regeneration in vivo. J. Neurosci. Res. 72, 646-659. doi: 10.1002/jnr.10589

Tarlov, I. M., Hoffman, W., and Hayner, J. C. (1946). Source of nerve autografts in clinical surgery. Am. J. Surg. 72, 700-710. doi: 10.1016/0002-9610(46) 90346-7

Toba, T., Nakamura, T., Lynn, A. K., Matsumoto, K., Fukuda, S., Yoshitani, M., et al. (2002). Evaluation of peripheral nerve regeneration across an $80-\mathrm{mm}$ gap using a polyglycolic acid (PGA)-collagen nerve conduit filled with lamininsoaked collagen sponge in dogs. Int. J. Artif. Organs 25, 230-237. doi: 10.1177/ 039139880202500310 
Urushibata, S., Hozumi, K., Ishikawa, M., Katagiri, F., Kikkawa, Y., and Nomizu, M. (2010). Identification of biologically active sequences in the laminin $\alpha 2$ chain G domain. Arch. Biochem. Biophys. 497, 43-54. doi: 10.1016/ j.abb.2010.03.006

Wang, A., Ao, Q., Cao, W., Yu, M., He, Q., Kong, L., et al. (2006). Porous chitosan tubular scaffolds with knitted outer wall and controllable inner structure for nerve tissue engineering. J. Biomed. Mater. Res. A 79, 36-46. doi: 10.1002/jbm. a.30683

Wang, H., Zhao, Q., Zhao, W., Liu, Q., Gu, X., and Yang, Y. (2012). Repairing rat sciatic nerve injury by a nerve-growth-factor-loaded, chitosanbased nerve conduit. Biotechnol. Appl. Biochem. 59, 388-394. doi: 10.1002/ bab. 1031

Wang, W., Itoh, S., Matsuda, A., Aizawa, T., Demura, M., Ichinose, S., et al. (2008a). Enhanced nerve regeneration through a bilayered chitosan tube: the effect of introduction of glycine spacer into the CYIGSR sequence. J. Biomed. Mater. Res. A 85, 919-928. doi: 10.1002/jbm.a.31522

Wang, W., Itoh, S., Matsuda, A., Ichinose, S., Shinomiya, K., Hata, Y., et al. (2008b). Influences of mechanical properties and permeability on chitosan nano/microfiber mesh tubes as a scaffold for nerve regeneration. J. Biomed. Mater. Res. A 84, 557-566. doi: 10.1002/jbm.a.31536

Wang, W., Itoh, S., Yamamoto, N., Okawa, A., Nagai, A., and Yamashita, K. (2010). Enhancement of nerve regeneration along a chitosan nanofiber mesh tube on which electrically polarized $\beta$-tricalcium phosphate particles are immobilized. Acta Biomater. 6, 4027-4033. doi: 10.1016/j.actbio.2010.04.027

Wang, X., Hu, W., Cao, Y., Yao, J., Wu, J., and Gu, X. (2005). Dog sciatic nerve regeneration across a $30-\mathrm{mm}$ defect bridged by a chitosan/PGA artificial nerve graft. Brain 128, 1897-1910. doi: 10.1093/brain/awh517

Wang, Y., Zhao, Y., Sun, C., Hu, W., Zhao, J., Li, G., et al. (2016). Chitosan degradation products promote nerve regeneration by stimulating schwann cell proliferation via miR-27a/FOXO1 axis. Mol. Neurobiol. 53, 28-39. doi: 10.1007/ s12035-014-8968-2

Wei, X., Lao, J., and Gu, Y. (2003). Bridging peripheral nerve defect with chitosancollagen film. Chin. J. Traumatol. 6, 131-134.

Wenling, C., Duohui, J., Jiamou, L., Yandao, G., Nanming, Z., and Xiufang, Z. (2005). Effects of the degree of deacetylation on the physicochemical properties and Schwann cell affinity of chitosan films. J. Biomater. Appl. 20, 157-177. doi: $10.1177 / 0885328205049897$

Woodbury, M. E., and Ikezu, T. (2014). Fibroblast growth factor-2 signaling in neurogenesis and neurodegeneration. J. Neuroimmune Pharmacol. 9, 92-101. doi: 10.1007/s11481-013-9501-5

Wu, H., Liu, J., Fang, Q., Xiao, B., and Wan, Y. (2017). Establishment of nerve growth factor gradients on aligned chitosan-polylactide /alginate fibers for neural tissue engineering applications. Colloids Surf. B Biointerfaces 160, 598-609. doi: 10.1016/j.colsurfb.2017.10.017

Xiao, W., Hu, X. Y., Zeng, W., Huang, J. H., Zhang, Y. G., and Luo, Z. J. (2013). Rapid sciatic nerve regeneration of rats by a surface modified collagen-chitosan scaffold. Injury 44, 941-946. doi: 10.1016/j.injury.2013. 03.029

Xu, C., Guan, S., Wang, S., Gong, W., Liu, T., Ma, X., et al. (2017). Biodegradable and electroconductive poly(3,4-ethylenedioxythiophene)/carboxymethyl chitosan hydrogels for neural tissue engineering. Mater. Sci. Eng. C 84, 32-43. doi: 10.1016/j.msec.2017.11.032

Xue, C., Hu, N., Gu, Y., Yang, Y., Liu, Y., Liu, J., et al. (2012). Joint use of a chitosan/PLGA scaffold and MSCs to bridge an extra large gap in dog sciatic nerve. Neurorehabil. Neural Repair 26, 96-106. doi: 10.1177/1545968311 420444

Yang, Y., Gu, X., Tan, R., Hu, W., Wang, X., Zhang, P., et al. (2004). Fabrication and properties of a porous chitin/chitosan conduit for nerve regeneration. Biotechnol. Lett. 26, 1793-1797. doi: 10.1007/s10529-0044611-z

Yao, M., Zhou, Y., Xue, C., Ren, H., Wang, S., Zhu, H., et al. (2016). Repair of rat sciatic nerve defects by using allogeneic bone marrow mononuclear cells combined with chitosan/silk fibroin scaffold. Cell Transplant. 25, 983-993. doi: 10.3727/096368916X690494

Yuan, Y., Zhang, P., Yang, Y., Wang, X., and Gu, X. (2004). The interaction of Schwann cells with chitosan membranes and fibers in vitro. Biomaterials 25, 4273-4278. doi: 10.1016/j.biomaterials.2003.11.029

Zeng, W., Rong, M., Hu, X., Xiao, W., Qi, F., Huang, J., et al. (2014). Incorporation of chitosan microspheres into collagen-chitosan scaffolds for the controlled release of nerve growth factor. PLoS One 9:e101300. doi: 10.1371/journal.pone. 0101300

Zhang, L., Yang, W., Tao, K., Song, Y., Xie, H., Wang, J., et al. (2017). Sustained local release of NGF from a chitosan-sericin composite scaffold for treating chronic nerve compression. ACS Appl. Mater. Interfaces 9, 3432-3444. doi: 10.1021/acsami.6b14691

Zhao, L., Qu, W., Wu, Y., Ma, H., and Jiang, H. (2014). Dorsal root ganglionderived Schwann cells combined with poly(lactic-co-glycolic acid)/chitosan conduits for the repair of sciatic nerve defects in rats. Neural Regen. Res. 9, 1961-1967. doi: 10.4103/1673-5374.145374

Zhao, Y., Wang, Y. Y. Y., Gong, J., Yang, L., Niu, C., Ni, X., et al. (2017). Chitosan degradation products facilitate peripheral nerve regeneration by improving macrophage-constructed microenvironments. Biomaterials 134, 64-77. doi: 10.1016/j.biomaterials.2017.02.026

Zheng, L., Ao, Q., Han, H., Zhang, X., and Gong, Y. (2010). Evaluation of the chitosan/glycerol- $\beta$-phosphate disodium salt hydrogel application in peripheral nerve regeneration. Biomed. Mater. 5:035003. doi: 10.1088/1748-6041/5/3/ 035003

Zhou, S., Yang, Y., Gu, X., and Ding, F. (2008). Chitooligosaccharides protect cultured hippocampal neurons against glutamate-induced neurotoxicity. Neurosci. Lett. 444, 270-274. doi: 10.1016/j.neulet.2008.08.040

Zhu, C., Huang, J., Xue, C., Wang, Y., Wang, S., Bao, S., et al. (2017). Skin derived precursor Schwann cell-generated acellular matrix modified chitosan/silk scaffolds for bridging rat sciatic nerve gap. Neurosci. Res. 135, 21-31. doi: 10.1016/j.neures.2017.12.007

Zivanovic, S., Li, J., Davidson, P. M., and Kit, K. (2007). Physical, mechanical, and antibacterial properties of chitosan/PEO blend films. Biomacromolecules 8 , 1505-1510. doi: 10.1021/bm061140p

Conflict of Interest Statement: The authors declare that the research was conducted in the absence of any commercial or financial relationships that could be construed as a potential conflict of interest.

Copyright (c) 2019 Boecker, Daeschler, Kneser and Harhaus. This is an open-access article distributed under the terms of the Creative Commons Attribution License (CC BY). The use, distribution or reproduction in other forums is permitted, provided the original author(s) and the copyright owner(s) are credited and that the original publication in this journal is cited, in accordance with accepted academic practice. No use, distribution or reproduction is permitted which does not comply with these terms. 